\title{
GETTING MORE "MILEAGE" Out of Oral Reading Tests
}

\author{
Caryl L. Adams
}

Diagnosis of a student's reading abilities is often carried out in the following way:

1. The student orally reads graded passages from an oral reading test or informal reading inventory.

2. The teacher or diagnostician marks an examiner's copy of the passages as the student reads, marking such errors as substitutions, omissions, insertions, repetitions, hesitations, and examiner pronunciations of words.

3. When the student finishes reading a passage, the examiner asks comprehension questions which accompany the passage.

4. The number of word recognition errors and the correct answers to the comprehension questions are counted.

5. The error total and comprehensions score are compared with criteria provided with the test or inventory, and the examiner determines if the student has passed or failed at that graded reading level. (The directions of most oral reading tests

Caryl L. Adams, PhD, is assistant professor, Reading Department, College of Education, University of Oklahoma, Norman, OK 73019. 
state something such as, "Stop testing when the student fails on either word recognition or comprehension.")

The following selection, read by Jimmy and marked with his word recognition errors and responses to comprehension questions, demonstrates this procedure.

Since Jimmy's oral reading errors place him at the frustration level on the word recognition portion of the task, this reading level would be considered too difficult for him (despite his 100 percent comprehension). Testing would be stopped, and his reading level would be established at a lower level of difficulty.

Has this determination of Jimmy's reading proficiency been accurate? Has the examiner learned anything about his reading except that "Jimmy makes many substitutions, fails to attend to endings of words, and his comprehension is good?"

For the teacher or diagnostician to truly determine Jimmy's (or any other student's) reading strengths and weaknesses, diagnosis must go beyond calculation of word recognition errors. As Goodman and Goodman (1977) have said, some errors are "better" than others because they don't change meaning, because the errors indicate that the student is relying on his knowledge of spoken language to supply a word that "fits" in a particular context, or because errors are a reflection of the student's dialect or experiential background. (See Figure 1 on following page.)

\section{Psycholinguistic Insights}

To make oral reading diagnosis a more accurate reflection of students' true reading abilities, teachers and diagnosticians must begin to make applications from the field of psycholinguistics to reading diagnosis.

Briefly, psycholinguistics is the study of how people learn, use, and understand language. Psycholinguistic knowledge has greatly enriched understanding of the reading process. The discipline also has much to offer one who wants to carry out diagnostic procedures using insights about the reader's real language capabilities, rather than simply focusing on his apparent oral reading production. 


\section{FIGURE 1}

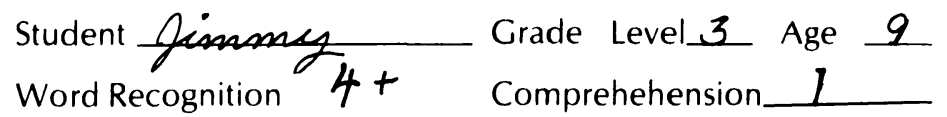

JOHN'S BIRTHDAY SURPRISE (Level 2)

Johnny
John rode his bicycle to the gró-y want floor wouldn't wanted him to buy flour and butter for her. She would not tell him why she wanted the flour and butter. Then Johnny remember gonna remembered. His birthday! She was going to bake a cake!

1. Where was John going? Like a Safeway

2. How did he get to the store? On his bike

3. Why was he going to the store? To get flour and butter

4. What did John think his mother would do with the flour and butter? Bake a cake

5. Why do you think John's mother did not tell him why she wanted the flour and butter? To surprise him

\section{SCORING CRITERIA}

Word Recognition Errors

Independent $0-1$

Instructional $2-3$

Frustration

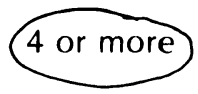

Comprehension Errors

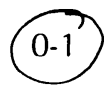

2

3 or more 
Psycholinguistic insights relevant to reading diagnosis are:

1. Reading goes beyond the surface level of "sounding out" words. Being able to say a word does not always indicate that one understands its meaning or its usage in a contextual setting.

This simple statement is readily apparent to anyone who has thoughtfully observed readers. All readers with an understanding of sound-symbol associations can pronounce words that have no meaning for them. And readers can often "read" all the words in context and have little or no understanding of that context.

2. Words can be omitted or identified incorrectly, and the reader can still understand the intent of the passage.

If a reader omits or miscalls a word there are often other clues in the context that reveal its meaning, or the reader can infer meaning from his experiential background.

In Jimmy's reading of the passage, consider the word grocery. He did not say grocery and yet his answer, "Like a Safeway," shows that Jimmy understood where John was going. Other clues to the meaning of grocery which were available to him in context were "buy flour and butter."

3. A student's oral language patterns are often reflected in his reading.

When Jimmy said bike instead of bicycle, wouldn't for would not, and gonna for going to, he was using the form of the words that many people use in an informal speaking situation. When he omitted the endings on wanted and remembered, he was, in fact, not "omitting an ending," but producing these words as he does in his oral language dialect.

4. Preservation of meaning is the most significant aspect of reading performance.

With these points in mind, a reexamination of Jimmy's oral reading errors is called for, this time considering not just the total number of errors, but also the number of significant errors-those likely to cause a loss of meaning. This type of oral reading analysis is based on the miscue analysis procedure (Goodman \& Goodman 1977). 


\section{Johnny
John rode his bicycle to the grocery store.}

Both substitutions Johnny and bike do not affect the meaning of the passage. Perhaps Jimmy said Johnny because he knows someone with that name. To say bike for bicycle, he had to understand the meaning of bicycle to produce the acceptable substitute of bike.

Jimmy's attempts at grocery show that he was applying phonics insights, but could not "sound out" the word because not enough meaning clues were available to him at this point.

Since it cannot be determined if Jimmy really understood the meaning of grocery here, this will be considered a "significant error."

$\begin{array}{lcc} & \begin{array}{c}\text { Error } \\ \text { Subtotal }\end{array} & \begin{array}{c}\text { Significant } \\ \text { Errors }\end{array} \\ \text { Word Recognition Errors } & 3 & 1 \\ \text { His mother wanted him to buy flour and butter. }\end{array}$

The substitution mom for mother shows that Jimmy understood the meaning of mother and produced an acceptable substitute, most likely what he calls his mother.

Want for wanted: In Jimmy's dialect, past tense verbs are not marked with -ed. Want is the equivalent in Jimmy's dialect of the standard English wanted. Meaning is still intact.

Floor for flour: This error indicates that Jimmy is again applying his insights about phonics but could not "sound out" the word successfully. This will be considered a "significant error."

$\begin{array}{ccc} & \text { Error } & \text { Significant } \\ \text { Subtotal } & \text { Errors } \\ \text { Word Recognition Errors } & 3 & 1 \\ \text { wouldn't } & \text { want } & \end{array}$

She would not tell him why she wanted the flour and butter.

Saying wouldn't and want are indications of Jimmy's reconstruction of the written message to sound like his spoken language. The meaning is preserved. 
Note that here Jimmy correctly identified flour, made possible by the build-up of information in the passage.

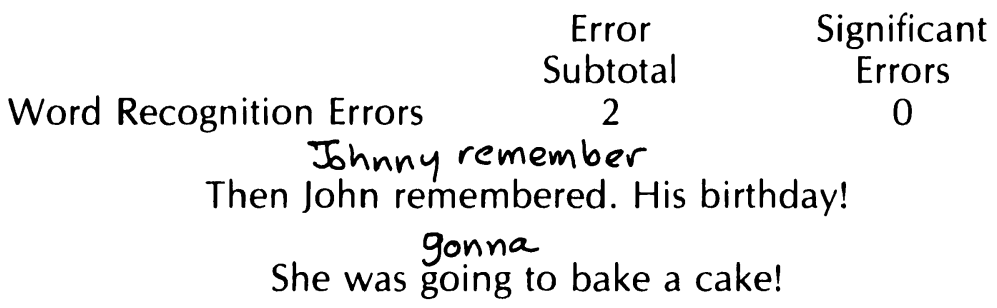

Again, Johnny, remember, and gonna are reflections of Jimmy's oral language production in the reading task.

$\begin{array}{ccc} & \begin{array}{c}\text { Error } \\ \text { Subtotal }\end{array} & \begin{array}{c}\text { Significant } \\ \text { Errors }\end{array} \\ \text { Word Recognition Errors } & 3 & 0\end{array}$

Total Word Recognition

Errors in the Passage 11

Errors Resulting from

Jimmy's Language 9

Total Significant Errors 2

The significant error floor was later correctly identified in the passage. Even though Jimmy's attempts at grocery were unsuccessful, he understood the meaning as indicated in his response to a comprehension question.

Analysis of Jimmy's reading in this manner reveals that in reality he is not reading at the frustration level, but at a proficient level, applying his knowledge of spoken language and retaining the meaning of what he has read.

His performance at the 2 nd grade readability level is not at the frustration level, but rather at the independent level, based on the number of significant oral reading errors and on his comprehension level. Testing would be continued to determine Jimmy's instructional and frustration reading levels.

\section{Comprehension Is the Goal}

Determination of independent, instructional, and frustra- 
tion levels in oral reading should not be based on total word recognition errors but on significant word recognition errors and on comprehension performance. Comprehension performance must be considered in any reading testing situation. If we value comprehsnion as a goal of reading instruction, we cannot discount it in a testing situation by determining a student's reading level on word recognition errors along.

Examination beyond the oral language surface (soundsymbol associations) reveals reading proficiencies never before noticed. The student's experiential and language background will explain much reading behavior. And, most significant, it will be discovered that at the meaning level there is often really no difference between the words on the page and the words the student produced. The teacher or diagnostician who begins to analyze oral reading by taking into consideration the language of the student will begin to discover some interesting facts about reading.

Reading diagnosis taking into consideration psycholinguistic insights will help you to focus on students' language strengths.

\section{References}

Goodman, Kenneth S. and Goodman, Yetta. 1977. Learning about psycholinguistic processes by analyzing oral reading. Harvard Educational Review 47:317-333.

ATP

\section{Odds 'n Ends}

Sale

Every year, in the spring, we find that we have odds ' $n$ ends of books that have been discontinued. In order to create room in our warehouse, we offer these at vastly discounted prices. If you're interested in a full list of these books, please write immediately. Sale ends July 1, 1982.

\section{GREAT DISCOUNTS!}

Write to: Special Sale, ATP, 20 Commercial Blvd., Novato, CA 94947 